\title{
Genetic Defects during Later Stages of Pituitary Development: The Clinical Phenotype of Pit-1 and Prop-1 Mutations
}

\author{
Roland Pfäffle, Oliver Blankenstein, Stephan Wüller and G. Heimann \\ Department Paediatrics, RWTH Aachen School of Medicine, Aachen, Germany
}

\begin{abstract}
Multiple pituitary hormone deficiency (MPHD) is associated with defects in transcription factors that are expressed during the development of the anterior pituitary gland. Genetic defects of factors with an expression during early pituitary development result in complex combinations of multiple pituitary hormone deficiencies with anatomical abnormalities of the central nervous system and midline structures (i.e. HesX-1 and Ptx-2). Mutations of transcription factors with an expression during late pituitary development (i.e. Pit-1 and Prop-1) create multiple pituitary hormone deficiency but little if any anatomical abnormality of the hypothalamo-pituitary area. Although the onset of the disorder is during the embryological development of the pituitary and both Pit-1 and Prop-1 mutations finally lead to severe forms of pituitary hormone deficiencies, the full clinical picture may only manifest itself after years of an insidious onset that can create some diagnostic problems. The molecular diagnosis of this disorder therefore gains importance in cases where in addition to Growth Hormone (GH) deficiency further hormonal deficits are suspected although they might not be clearly evident. Ongoing research concentrates on further factors involved in the differentiation and proliferation of cells that belong to the hypothalamo-pituitary growth axis.
\end{abstract}

Key words: isolated growth hormone deficiency, multiple pituitary hormone deficiency, Pit-1, Prop-1, pituitary mass

\section{Introduction}

\section{Causes for Growth Hormone Deficiency (GHD)}

GH deficiency can be due to a variety of inborn or acquired defects in the hypothalamo-pituitary system. The estimates about the frequency of this disorder differ significantly and range from

Correspondence to: Dr. Roland W. Pfäffle, Department of Paediatrics, RWTH Aachen School of Medicine, 52074 Aachen, Germany

e-mail:rpfaeffle@post.klinikum.rwth-aachen.de
1:4,000 to 1: $10,000(1,2)$. International Growth Hormone $(\mathrm{GH})$ treatment studies however demonstrate that in far less than half of the patients GHD can be attributed to organic causes like peripartal trauma, tumours or infection $(3,4)$.

In most instances of trauma related multiple pituitary hormone deficiency there is $\mathrm{GH}$ deficiency, because the GH producing somatotrophs make up more than 50\% percent of the pituitary cell mass and physical damage to this gland therefore is most likely to impair the secretory reserve for GH. Nearly similar in frequency are deficiencies of LH and FSH, whereas 
thyrotroph and corticotroph function seems somewhat more resistant to trauma.

\section{Inherited forms of GHD}

The majority of the cases with pituitary insufficiency seem to occur spontaneously although in $5-30 \%$ of this group multiple occurrences in the family suggest some kind of genetic background (5):

Isolated Growth Hormone Deficiency (IGHD): Genetic causes of IGHD are suspected in factors that belong to the signalling cascades which functionally are members of the hypothalamopituitary GH axis. The two factors where such mutations have been identified so far are the Growth Hormone Releasing Hormone Receptor (GHRHR) and GH1 itself. Although many different mutations or deletions have been identified both in autosomal dominant and recessive forms of GHD, in a not preselected cohort of patients with IGHD these two forms can account for only less than $5 \%$ of all patients. Further members of the hypothalamo-pituitary Growth Axis have been studied (i.e. GHRH gene itself) however no frequent genetic cause for IGHD has been identified so far.

Multiple pituitary hormone Deficiency (MPHD): Inherited forms of multiple pituitary hormone deficiency show different patterns of hormone deficiency than the ones caused by trauma or infection. A mutation will affect a specific combination of pituitary cells which will depend primarily on the affected gene. So far genetic defects have been identified in transcription factors involved in pituitary organogenesis (6). These are DNA-binding proteins expressed primarily in the forebrain, most of which belong to the family of homeodomain transcription factors (7). Their timely appearance (and disappearance) during embryogenesis follows a certain expression pattern that is interdependent. Not all of these regulatory mechanisms are well understood, and presumably not all transcription factors of pituitary differentiation are known yet.

The differentiation of the pituitary

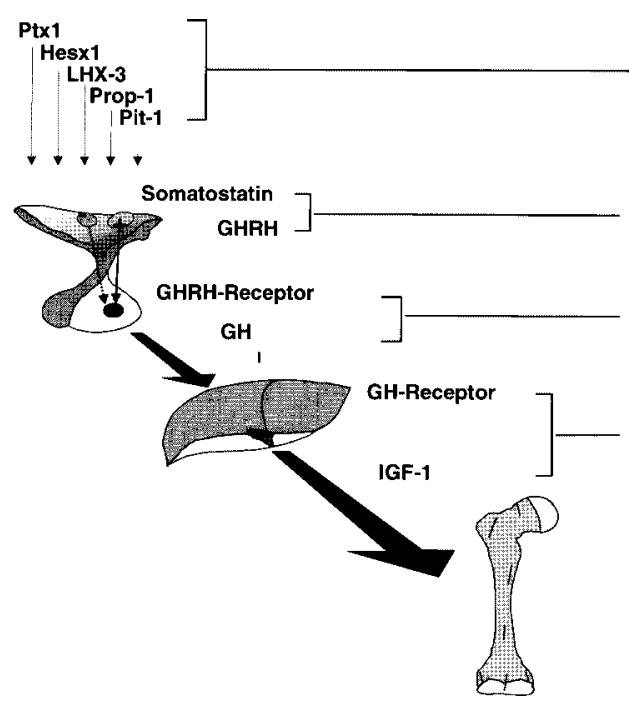

Disturbed Development of the Anterior Pituitary

Hypothalamic Defects of GH-Secretion

Pituitary Defects of GH-synthesis and secretion

Resistance to GH-secretion

(Laron-Syndrome)

Fig. 1 Different factors possibly involved in the pathogenesis of GHD at a molecular level. Genetic defects within pituitary transcription factors (HesX1, LHX-3, Prop-1 and Pit-1) have been identified as causing developmental defects of the pituitary gland resulting in various forms of MPHD. Factors printed in grey have not yet been identified as a cause of GHD. 
somatotrophs, and lactotrophs is the last differentiation step of hormone producing cells in the pituitary. This is the most likely reason why in genetic MPHD somatotrophs and lactotrophs are always affected together.

Thyrotrophs also share part of the pituitary differentiation steps together with somatolactotrophs, which explains why secondary hypothyroidism often additionally occurs in patients with GH and Prl deficiency. Finally, although the regulation of the differentiated gonadotroph cells differ completely from the array of other pituitary cells, during earlier stages of cell differentiation they share a common transcription factor (Prop-1). Secondary hypogonadism therefore is present in all patients with Prop-1 gene defects.

The most eminent question for the clinician however is, when hypogonadism will appear in his patient and how severe it will be. Interestingly, the severity of each of these hormone deficiencies can vary quite considerably among patients with genetic forms of MPHD. This article will try to give an account of which factors are relevant for the phenotypic expression of the disorders caused by Pit-1 and Prop-1 gene defects.

\section{Identification of Factors Affecting GH Gene Transcription and Pituitary Organogenesis}

\section{Identification of Pit-1, studying GH gene reg- ulation}

GH synthesis accounts for a major proportion of protein synthesis in the anterior pituitary gland; approximately $3 \%$ of all pituitary-derived mRNA corresponds to the GH gene (8). The pituitary with an average weight of app. $500 \mathrm{mg}$ produces 1-3 mg of GH each day. GH synthesized in other tissues than the pituitary can be detected however they have physiological relevance to growth. The regulatory mechanism involved in GH synthesis therefore has to be pituitary-specific and highly efficient at the same time.

$\mathrm{GH}$ gene transcription is regulated by numerous transcription factors, among which the pituitary transcription factor Pit-1 (9) plays a pivotal role. Pit-1 was initially identified as a protein that binds to the promoter of the GH gene promoter. The GH gene carries two binding sites for Pit-1 that were highly conserved during evolution from fish to humans (10).

Shortly thereafter it was realised that Pit-1 is expressed not only in somatotrophs but in three distinct pituitary cell lines (somatotrophs, lactotrophs and thyrotrophs), which reflects its pluripotent role on cell differentiation during pituitary development. Thyrotrophs seem to arise from two independent cell populations in mice (11). The first cell population is Pit-1 independent and only transiently present; it appears around e 12 in the rostral tip of the pituitary gland prior to the first detectable Pit-1 expression on e14.5. The second proportion of cells is Pit-1 dependent and arises thereafter on day 15.5 after Pit-1 is expressed in this area.

Despite its early expression during pituitary cell differentiation Pit-1 can be detected throughout life, which also demonstrates its importance as a modulator of GH and Prl and most probably TSH synthesis and secretion, too.

The various physiological characteristics of Pit-1 have been initially studied in the mouse (11). GH-, PRL- and TSH- deficiency is the characteristic pituitary defect of the Snell-, Jackson- and Amesdwarf mice (12). Whereas mutations of the Pit-1 gene were found in the Jackson $\left(d w^{\mathrm{J}}\right)$ and Snell (dw) dwarf mice (13), no such changes could be detected in the Pit-1 gene of Ames-dwarf mice.

\section{Identification of Prop-1 - studying dwarf Ames mice}

The Ames dwarf locus $(d f)$ is located on a different mouse chromosome than the Pit-1 gene (chr 11 instead of chr 16) (14). The $d f$ locus was further localized by Sornson and co-workers with the help of modern positional cloning techniques (15). They identified a factor with an expression during pituitary development limited to those cells 
that subsequently are found to express Pit-1. Prop1 is first detected at e10 in the mouse embryo, most of which is detectable over the dorsal portion of the gland. A maximum of Prop-1 expression is detected by e12 in the caudomedial region, where later Pit-1 is expressed (16). Analysis of double mutants revealed that the growth-retarded phenotype of the Ames mouse prevails over the Snell and Jackson mouse phentotypes. Sornson and co-workers therefore named the newly identified transcription factor the 'Prophet of Pit-1' or Prop-1 (15).

The Ames dwarf mouse has a homozygous mutation which involves a serine to proline substitution at aminoacid 83 (S83P) in the first alpha helix of the homeodomain. These animals have a deficiency for GH, Prl and TSH, however they show normal initial stages of pituitary development. At e13 in the mouse, pituitary cells in the caudomedial region fail to express Pit-1 and thereby Pit-1 dependant pituitary lineages do not differentiate and proliferate. The size of the pituitary gland is visibly reduced by day e14.5, and the size of the adult pituitary is reduced by approximately $2 / 3$.

The adult Ames dwarf mouse shows severe GH deficiency with less than 1\% of the normal somatotrophs, and scarcity of lactotrophs and thyrotrophs. There is also reduced expression of gonadotropins.

\section{Structure and Function of Pit-1 and Prop-1}

A number of alternative names have been assigned to Pit-1 (pituitary transcription factor 1), which include GHF1 (GH factor 1) and POU1F1.

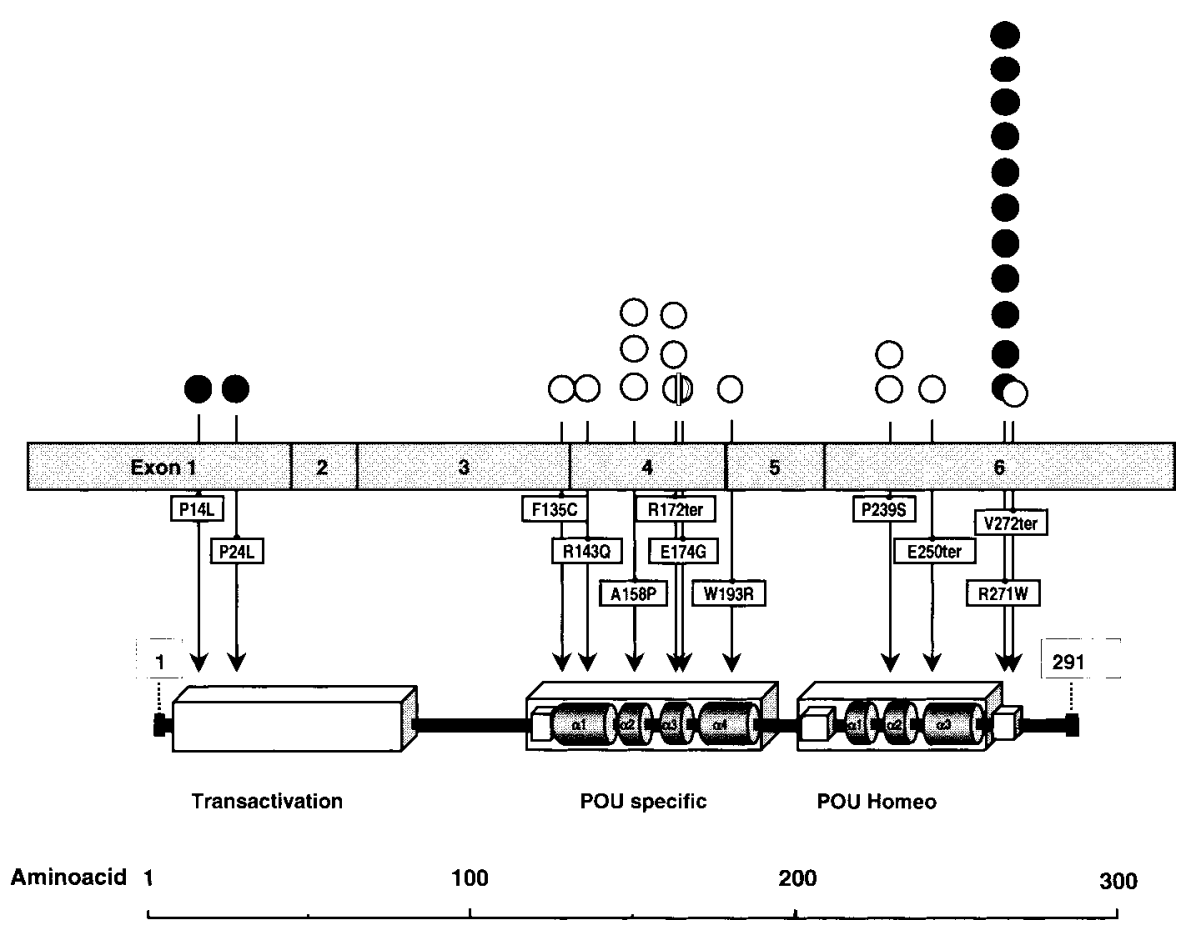

Fig. 2 Relative positions of mutations within the Pit-1 gene as described so far. Closed circles symbolise mutations that have a reported autosomal dominant type of inheritance, open circles show a recessive inheritance pattern. Half-circles show position of mutation encountered in patients with compound heterozygosity (further explanations see text). 
Here we use the term Pit-1 which has the widest acceptance. POU is an acronym of Pit, Oct and Unc, which are all related transcription factors from a variety of different organisms with similar DNA binding domains. The human Pit-1 gene is located on chromosome 3p11 and consists of six exons spanning a region of $17 \mathrm{~kb}$ of the DNA sequence. The Pit-1 gene encodes a protein of 291 amino acids with a molecular mass of $33 \mathrm{kDa}$. The protein has three functional domains which include a transactivation domain and two DNA binding domains-a POU-specific domain and a POUhomeodomain. The POU homeodomain has a nearly identical structure to that seen in many of the homeobox genes, i.e. a highly conserved region of 180 nucleotides encoding a 60 amino acid DNA binding domain within the protein. The POU homedomain specifically recognizes and binds to A-T rich regions in DNA, while the POU-specific domain enhances this by binding co-operatively at the consensus sequence TATNCAT (where $\mathrm{N}$ is an unspecified nucleotide). The promoter regions of the genes encoding GH and CSH have two such Pit1 consensus binding sites. Three Pit- 1 binding sites have also been reported in the prolactin promoter. Interestingly, binding sites have also been demonstrated in the promoter region of Pit-1, which suggests an auto-regulatory control of Pit-1 expression. The initial Pit-1 transcription however appears in the absence of Pit-1 protein, and in the Snell-mouse Pit-1 gene transcripts can be detected until day 5 after birth (17). This suggests that Pit1 is necessary for sustained Pit- 1 transcription in the pituitary gland.

Prop-1 is a 'paired'-like homeobox gene, which has been mapped to chromosome $5 q$ in the human genome. The term Prop- 1 is an acronym of Prophet of Pit-1. This nomenclature was used because the Prop-1 protein product precedes and promotes the expression of Pit- 1 . The Prop-1 gene consists of

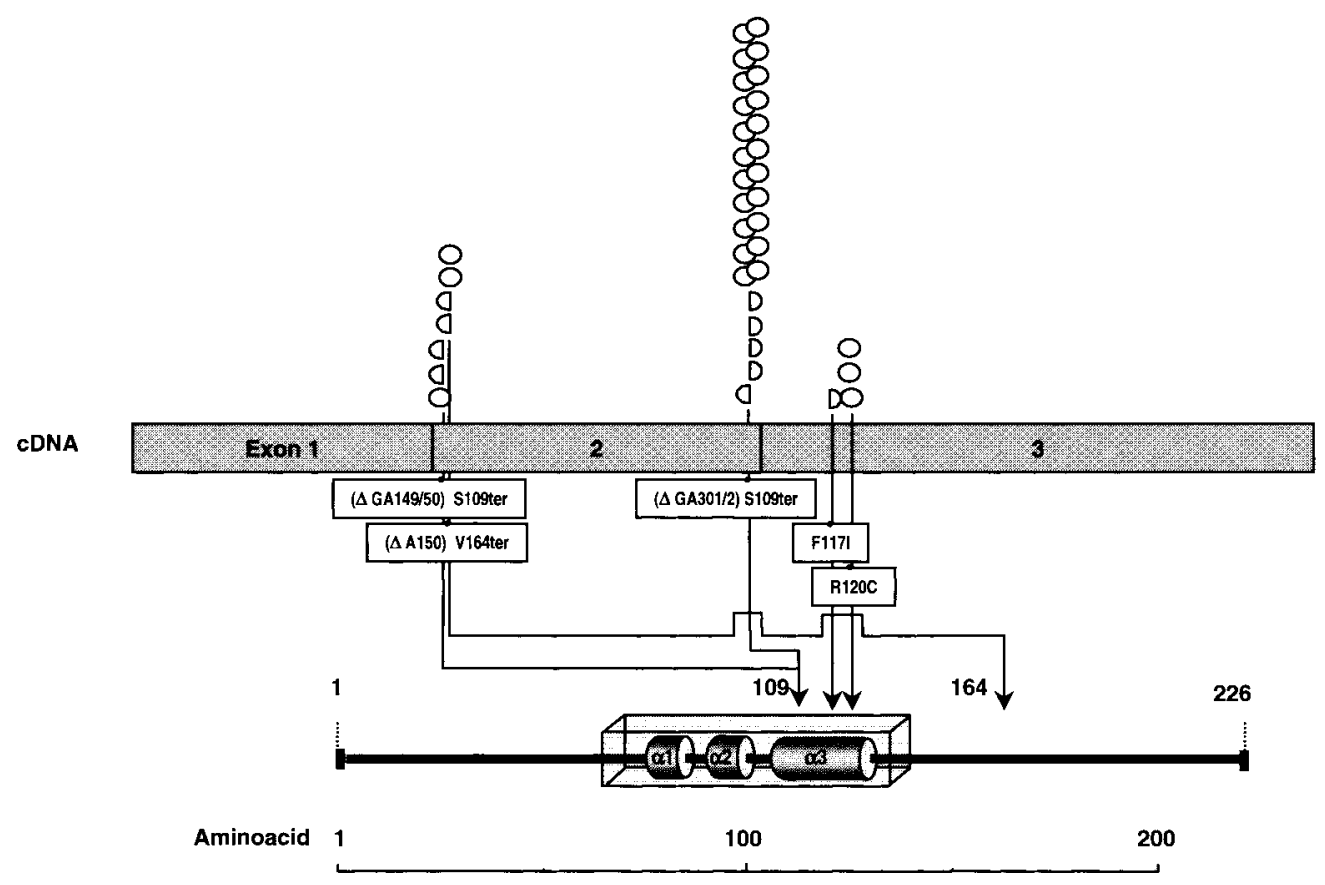

Fig. 3 Relative position of Prop-1 mutations in humans. Two hotspot regions have been observed so far. Both mutations (A150 and GA 301/2) induce frame-shifts (symbolised by the horizontal part of the line) with the introduction of early translational stop codons in positions 109 and 164 respectively. All mutations affect DNA-binding (further explanations see text). 
Table 1

\begin{tabular}{lllll}
\hline $\begin{array}{l}\text { Transcription } \\
\text { Factor }\end{array}$ & $\begin{array}{l}\text { Expression } \\
\text { during mouse } \\
\text { pituitary } \\
\text { development }\end{array}$ & $\begin{array}{l}\text { Site of } \\
\text { expression }\end{array}$ & $\begin{array}{l}\text { Animal } \\
\text { Model for } \\
\text { gene defect } \\
\text { (mouse) }\end{array}$ & $\begin{array}{l}\text { Known Function } \\
\text { (Possible Function*) }\end{array}$ \\
\hline Prop-1 & E10-E15 & $\begin{array}{l}\text { Rathke's pouch } \\
\text { (somato-, lacto-, } \\
\text { thyro- and } \\
\text { gonadotroph cells) }\end{array}$ & Ames-dwarf mouse & $\begin{array}{l}\text { Proliferation of cells } \\
\text { that later express Pit-1, } \\
\text { differentiation of } \\
\text { gonadotroph cells. }\end{array}$ \\
\hline $\begin{array}{l}\text { Pit-1 } \\
\text { (POU1F1) }\end{array}$ & E 13.5- & $\begin{array}{l}\text { Rathke's pouch } \\
\text { (somato-, lacto- } \\
\text { and thyreotroph cells) }\end{array}$ & $\begin{array}{l}\text { Snell- and } \\
\text { Jackson } \\
\text { dwarf mice }\end{array}$ & $\begin{array}{l}\text { Differentiation and } \\
\text { proliferation of somato-, } \\
\text { lacto- u. thyreotroph cells. }\end{array}$ \\
\hline
\end{tabular}

Transcription Factors with a role in pituitary development $\left({ }^{*}\right.$ possible functions deduced from analysis of mouse mutants; $\mathrm{E}=$ embryonic day).

three exons spanning a compact region of about 3 $\mathrm{kb}$ in length encoding a protein of 226 amino acids. The protein contains a central DNA binding domain with three $\alpha$ helical regions that resemble the 'paired' domains characteristic of the Drosophila transcription factors involved in determining cell fate during embryonic development. In addition to the DNA binding domain, the protein also possesses a transcriptional activation domain involved in the auto-regulatory control of Prop-1 expression. Like other 'paired' like proteins, the Prop-1 protein recognizes and binds to palindromic sequences located within the promoter elements of other target genes. The protein binds to these sequences in vivo as a dimer.

\section{Hormonal Phenotypes}

\section{Pit-1 mutations}

The first human mutation in Pit- 1 was reported in 1992 in a child with combined GH and PRL deficiency (18). In addition the patient exhibited profound hypothyroidism suggestive of a defect in TSH production. The patient was homozygous for a nonsense mutation at codon 172 , which resulted in the production of a severely truncated protein. The mutant protein lacks both of the DNA binding domains and is therefore incapable of binding to GH, PRL and TSH promoters and activating their expression. There is a rather uniform phenotype of patients found to have PIT1 gene mutations. They show multiple pituitary hormone deficiency (MPHD) with lack of GH, PRL and TSH (19). GH and PRL serum levels are below detection limits, while low serum levels of TSH can still be detected. However, these TSH levls are too low to prevent secondary hypothyroidism in these patients. Whereas GH deficiency seems unequivocal in all patients with Pit-1 deficiency, hypothyroidism can be more or less severe. In some patients hypothyroidism is the leading clinical symptom right after birth, whereas in others it occurs only after GH substitution therapy. Severe Prl deficiency is present presumably from birth on, in patients with Pit-1 mutation, however lack of symptoms usually makes this an incidental finding during testing procedures for pituitary insufficiency.

MPHD due to Pit-1 gene mutations have been shown to be inherited in an autosomal recessive mode $(18,20)$. In other pedigrees the disorder seems to follow an autosomal dominant mode of inheritance $(21,22)$.

All mutations that cause changes within the DNA-binding domain of Pit-1 show an autosomal 
recessive type of inheritance because many mutations affecting the structure of the helix-turnhelix motif are likely to impair the sequencespecific binding of the protein. Pit-1 mutations with autosomal dominant inheritance are found outside the DNA-binding domain and most likely do not impair the binding of Pit-1 to DNA target sequences. This could explain the dominant negative effect of this mutation (21).

There seems to be one "hotspot" for mutations within the Pit-1 gene which causes the R271W mutation that is observed in pedigrees with an autosomal dominant type of inheritance of MPHD. This may be both due to the sequence at this specific site of the gene which carries a so called CpG-dinucleotide and the dominant negative effect that this mutation induces.

\section{Prop-1 mutations}

When patients with a combined pituitary hormone deficiency of GH, PRL and TSH were screened for Prop-1 mutations, no defects were identified. Patients however that showed a broader spectrum of pituitary hormone deficiencies carried Prop-1 mutations. This made it clear that the phenotype of patients with Prop-1 mutations differs somewhat from that of patients with Pit-1 mutations, and also that the phenotype found in humans differed from that of Ames mice, although insufficient gonadotropin secretion has also been observed in Ames mice (15).

Prop-1 gene mutations cause a combined pituitary hormone deficiency that includes LH and FSH in addition to GH, PRL and TSH (23).

The deficiencies for GH and Prl is severe although in contrast to most patients with Pit-1 mutations GH can be detected in serum from patients with Prop-1 mutations.

TSH deficiency is not present in all affected persons right after birth. TSH levels when measured early during infancy are detectable and if tested by TRH stimulation they even show a delayed increase.

This in some instances leads to the diagnosis of tertiary or hypothalamic hypothyroidism. A similar condition holds true for the gonadotroph cell line. Although secondary hypogonadism finally develops in all patients with Prop-1 defects the onset again can be insidious and in some patients initial signs of puberty could be detected (24). The clinical variability of Prop-1 mutations during the first years of life therefore is much more variable in comparison to that caused by Pit-1 mutations. Considering the fact that such variability can be observed even among patients with identical mutations the mechanisms for this are not clear yet. Two reasons however could account for this: in pituitaries with mutant Prop-1 the lack of pituitary cell lines is not as complete as that observed in pituitaries with Pit-1 gene mutations (15). Some cells just might even progress to further proliferation in the presence of defect Prop-1. Secondly the effects of Prop-1 are exerted during a limited time of pituitary differentiation, Pit-1 instead has an important role in target gene activation also in the adult individuum. This could add to the profoundness of the Pit-1 phenotype. All Prop-1 mutations described so far are inherited in an autosomal recessive way and all at least presumably affect DNA-binding.

Two hotspots have been identified. These both involve microdeletions. The 2-bp $\Delta$ GA301/2 deletion (23) and the $\Delta \mathrm{GA} 149 / 50$ or $\Delta \mathrm{A} 150$ frameshift mutations both found within exon 2 . They introduce early stop codons at positions 109 and 164, respectively (25). The Prop-1 molecules resulting from those two mutations have no sequences corresponding to the highly conserved DNA-binding domain. In patients with Prop-1 mutations a combination of GH, PRL, TSH and gonadotropin deficiency is detectable, the age of the patients at the time of diagnosis however varies considerably (26). 
Table 2

\begin{tabular}{llll}
\hline $\begin{array}{l}\text { Transcription } \\
\text { Factor }\end{array}$ & $\begin{array}{l}\text { Hormonal Phenotype } \\
\text { (deficiencies for) }\end{array}$ & Inheritance & $\begin{array}{l}\text { Pituitary } \\
\text { morphology }\end{array}$ \\
\hline Pit-1 & GH, Prl, TSH & $\begin{array}{l}\text { Dominant } \\
\text { Recessive }\end{array}$ & Reduced size \\
\hline Prop-1 & GH, Prl, TSH, & Recessive & $\begin{array}{l}\text { Reduced size } \\
\text { Lometimes intra-or } \\
\text { LH/FSH }\end{array}$ \\
& & & suprasellar enlargment \\
\hline
\end{tabular}

\section{Pituitary Morphology in Pit-1 and Prop-1 Patients}

The average weight of an adult pituitary gland is approximately $600 \mathrm{mg}$, however there are significant interindividual differences (400-900 mg). Although MR-tomography gives an excellent picture of hypothalamo-pituitary anatomy it is not possible to judge from pituitary size its functional capacity. From pituitary imaging, patients with Pit-1 or Prop-1 mutations have small (app. 1/3 rd of normal) anterior pituitary glands compared with those of age-matched healthy individuals (27). There seems to be no significant difference in the size of the pituitary gland in patients with Pit-1 mutations versus those with Prop-1 mutations (28).

MR-imaging can be helpful in classifying a certain type of pituitary insufficiency and linking the defect to a specific stage of pituitary development, it however cannot be proof for one or the other genetic defect.

An increasing number of authors have observed intra- and suprasellar enlargment of the pituitary gland in patients with Prop-1 defects (29, 30). Although these space occupying lesions have never been reported to result in secondary sequelae like visual loss or headache, they can be irritating to both patient and attending physician. Surgery is not recommended as they regress spontaneously, sometimes in the course of only a few months. The nature of these masses still is unclear. One hypothesis is that the defect Prop-1 might fail to repress some early pituitary transcription factors. This prolonged expression might give rise to such pituitary enlargement. A prolonged expression of LHX-3 has been observed in the Ames mouse (15).

\section{Frequency of Pit-1 and Prop-1 Gene Defects}

Mutations within one of the above mentioned genes are rarely described. Usually only patients with severe forms of GHD are thought to be eligible for molecular analyses. It therefore remains somewhat unclear what proportion of patients with idiopathic GHD have a genetically defined background.

So far not all forms of MPHD can be explained. In our experience approximately half of all patients with a deficiency for GH, TSH and prolactin have detectable mutations within their Pit-1 gene, whereas at least two thirds of the patients with a deficiency of GH, TSH, prolactin and gonadotropins have mutations within their Prop-1 gene. So far experience with transcription factors that are expressed earlier during pituitary development (like HesX-1 and LHX-3) are limited to delineating a hormonal phenotype or to giving clear estimate about the frequency of such mutations. According to our preliminary results such mutations occur rarely, accounting for less than $1 \%$ of patients with MPHD. It is clear however that the characterisation of further and so far unknown pituitary differentiation factors will add to the proportion of classifiable pituitary disorders 
in the future and thereby hopefully will enhance our diagnostic accuracy in patients with idiopathic GHD.

\section{References}

1. Lacey KA, Parkin JM. Causes of short stature. A community study of children in Newcastle upon Tyne. Lancet 1974; 1: 42-5.

2. Vimpani GV, Vimpani AF, Lidgard GP, Cameron $\mathrm{EH}$, et al. Prevalence of severe growth hormone deficiency. Brit Med J 1977; 2: 427-30.

3. Phillips JA. Inherited defects in growth hormone synthesis and action. In: Scriver CR, Beaudet AL, Sly WS, Valle D, editors. The metabolic basis of inherited disease. New York: McGraw-Hill; 1995; 3023-44.

4. Wilton P, Wallstrom A. An overview of the diagnoses in the Kabi Pharmacia International Growth Study. Acta Paediatr Scand (Suppl) 1991; 379: 93-8.

5. Procter AM, Phillips JA, 3rd, Cooper DN. The molecular genetics of growth hormone deficiency. Hum Genet 1998; 103: 255-72.

6. Rosenfeld MG, Bach I, Erkman L, Li P, et al. Transcriptional control of cell phenotypes in the neuroendocrine system. Recent Prog. Horm. Res. 1996; 51: 217-38.

7. Gehring WJ, Hiromi Y. Homeotic genes and the homeobox. Annu Rev Genet 1986; 20: 147-73.

8. Chen EY, Liao YC, Smith DH, Barrera-Saldana HA, et al. The human growth hormone locus: nucleotide sequence, biology, and evolution. Genomics 1989; 4: 479-97.

9. Ingraham HA, Chen RP, Mangalam HJ, Elsholtz $\mathrm{HP}$, et al. A tissue-specific transcription factor containing a homeodomain specifies a pituitary phenotype. Cell 1988; 55: 519-29.

10. Argenton F, Vianello S, Bernardini S, Jacquemin $\mathrm{P}$, et al. The transcriptional regulation of the growth hormone gene is conserved in vertebrate evolution. Biochem Biophys Res Commun 1993; 192: 1360-6.

11. Simmons DM, Voss JW, Ingraham HA, Holloway $\mathrm{JM}$, et al. Pituitary cell phenotypes involve cellspecific Pit-1 mRNA translation and synergistic interactions with other classes of transcription factors. Genes Dev 1990; 4: 695-711.

12. Duquesnoy RJ. The pituitary dwarf mouse: a model for study of endocrine immunodeficiency disease. Birth Defects Orig Artic Ser 1975; 11: 536-43.

13. Li S, Crenshaw EBd, Rawson EJ, Simmons DM, et al. Dwarf locus mutants lacking three pituitary cell types result from mutations in the POUdomain gene pit-1. Nature 1990; 347: 528-33.

14. Buckwalter MS, Katz RW, Camper SA. Localization of the panhypopituitary dwarf mutation (df) on mouse chromosome 11 in an intersubspecific backcross. Genomics 1991; 10: 515-26.

15. Sornson MW, Wu W, Dasen JS, Flynn SE, et al. Pituitary lineage determination by the Prophet of Pit-1 homeodomain factor defective in Ames dwarfism. Nature 1996; 384: 327-33.

16. Dutour A. A new step understood in the cascade of tissue-specific regulators orchestrating pituitary lineage determination: the Prophet of Pit-1 (Prop1). Eur J Endocrinol 1997; 137: 616-7.

17. Rhodes SJ, Chen R, DiMattia GE, Scully KM, et al. A tissue-specific enhancer confers Pit-1-dependent morphogen inducibility and autoregulation on the pit-1 gene. Genes Dev 1993; 7: 913-32.

18. Tatsumi K, Miyai K, Notomi T, Kaibe K, et al. Cretinism with combined hormone deficiency caused by a mutation in the PIT1 gene. Nat Genet 1992; 1: 56-8.

19. Pfäffle RW, Kim C, Otten B, Wit JM, et al. Pit-1: clinical aspects. Horm Res 1996; 45: 25-8.

20. Pfäffle RW, DiMattia GE, Parks JS, Brown MR, et al. Mutation of the POU-specific domain of Pit-1 and hypopituitarism without pituitary hypoplasia. Science 1992; 257: 1118-21.

21. Radovick S, Nations M, Du Y, Berg LA, et al. A mutation in the POU-homeodomain of Pit-1 responsible for combined pituitary hormone deficiency. Science 1992; 257: 1115-8.

22. Ohta K, Nobukuni Y, Mitsubuchi H, Fujimoto S, et al. Mutations in the Pit-1 gene in children with combined pituitary hormone deficiency. Biochem Biophys Res Commun 1992; 189: 851-5.

23. Wu W, Cogan JD, Pfäffle RW, Dasen JS, et al. Mutations in PROP1 cause familial combined pituitary hormone deficiency. Nat Genet 1998; 18: 147-9. 
24. Fluck C, Deladoey J, Rutishauser K, Eble A, et al. Phenotypic variability in familial combined pituitary hormone deficiency caused by a PROP1 gene mutation resulting in the substitution of Arg$\rightarrow$ Cys at codon 120 (R120C) [In Process Citation]. J Clin Endocrinol Metab 1998; 83: 3727-34.

25. Fofanova O, Takamura N, Kinoshita E, Parks JS, et al. Compound heterozygous deletion of the PROP1 gene in children with combined pituitary hormone deficiency. J Clin Endocrinol Metab 1998; 83: 2601-4.

26. Fluck C, Deladoey J, Rutishauser K, Eble A, et al. Phenotypic variability in familial combined pituitary hormone deficiency caused by a PROP1 gene mutation resulting in the substitution of Arg$\rightarrow$ Cys at codon 120 (R120C). J Clin Endocrinol Metab 1998; 83: 3727-34.

27. Fofanova O, Takamura N, Kinoshita E, Vorontsov A, et al. MR imaging of the pituitary gland in children and young adults with congenital combined pituitary hormone deficiency associated with PROP1 mutations. AJR Am J Roentgenol 2000; 174: 555-9.

28. Pfaffle RW, Blankenstein O, Wuller S, Kentrup H. Combined pituitary hormone deficiency: role of Pit-1 and Prop-1. Acta Paediatr (Suppl) 1999; 88: 33-41.

29. Mendonca BB, Osorio MG, Latronico AC, Estefan $\mathrm{V}$, et al. Longitudinal hormonal and pituitary imaging changes in two females with combined pituitary hormone deficiency due to deletion of A301,G302 in the PROP1 gene [In Process Citation]. J Clin Endocrinol Metab 1999; 84: 9425.

30. Rosenbloom AL, Almonte AS, Brown MR, Fisher DA, et al. Clinical and biochemical phenotype of familial anterior hypopituitarism from mutation of the PROP1 gene. J Clin Endocrinol Metab 1999; 84: $50-7$. 